\title{
Intravenous-to-oral conversion therapy for antimicrobials
}

A NTIMICROBIAL AGENTS ARE TYPICALLY RESPONSIBLE FOR 25 to $40 \%$ of the total medication costs in hospitals in North America $(1,2)$ and are often the focus of cost containment efforts $(3,4)$. Cost containment programs can be approached using several different methods, which are used by most institutions to varying degrees. Some of these methods include educational programs, use of a hospital formulary, selected sensitivity reporting from the microbiology laboratory, conversion programs, automatic stop orders and substitutions, antimicrobial treatment guidelines, controlled antimicrobials and control of in-hospital pharmaceutical company activities (1). Most of the reviews of cost containment programs have emphasized the need for improved education and, from a pragmatic standpoint, the efficacy of each method depends on whether it meets the needs of the practising clinician.

Conversion programs may be considered in the context of dosage, interval and route, or any combination thereof. Although conversions from higher to lower dosages and from shorter to longer intervals have been used for many years, early conversion from intravenous to oral therapy in the hospitalized patient has never received much emphasis. A formal conversion program from intravenous to oral, also referred to as 'switch' therapy (5), or 'step-down' therapy (6) is not novel, but if utilized to its full extent represents a unique and exciting opportunity to reduce costs significantly while improving the quality of patient care.

Although some clinicians are hesitant to initiate early transition to oral anti-infective therapy or to change the regimen of a patient who is demonstrating signs of improvement, there is increasing evidence to support the early use of oral agents in the treatment of several infectious diseases $(4,7)$. Several studies have assessed the efficacy of oral antimicrobial therapy in various infections, including respiratory tract infections $(8,9)$, skin and soft tissue infections $(10,11)$, and bone and joint infections (12-14), and have provided considerable evident to suggest that the use of oral agents is both safe and efficacious. For many years our pediatric colleagues have treated children with acute osteomyelitis with oral agents after an initial (usually five to seven days) response to parenteral therapy, and gonococcal septic arthritis is often treated with oral therapy alone or after a brief course of parenteral therapy $(15,16)$. The treatment of intra-abdominal infections or anaerobic brain abscesses (17) may be treated with oral as opposed to intravenous metronidazole. With the exception of patients with infections in areas into which antibiotic penetration is poor (ie, meningitis and infective endocarditis), the majority of hospitalized patients does not require prolonged courses of parenteral therapy.

Additional supporting evidence for the use of oral antimicrobials earlier in the course of treatment for infectious diseases may be found by a careful analysis of the pharmacokinetics of many antimicrobials. Several agents, including metronidazole, clindamycin, amoxicillin, trimethoprim-sulfamethoxazole, ciprofloxacin, ofloxacin, doxycycline and cephalexin, achieve high serum levels and excellent tissue penetration when given orally. The bioavailability of these agents suggests that they could be expected to achieve clinical results similar to intravenous preparations in patients with a normal absorptive capacity. Identification of patients for whom early conversion to oral therapy may be used must be individualized based on the patient's clinical status, lack of evidence suggesting malabsorption and ability to take medications orally. With the exception of endocarditis, meningitis and the initial treatment of the febrile neutropenic host, most patients may be considered for conversion therapy.

Several studies have considered the economic impact $(6,8,18)$ of conversion therapy, and these investigations suggest that significant cost savings may be achieved through a reduction in direct acquisition costs, the absence of a need for special supplies required for intravenous medication, the decrease in related pharmacy and nursing labour and the ability to shorten length of stay. The relative ease of preparation, storage and administration of oral medications also makes this mode of administration more convenient as well as less expensive.

A pilot study at The Toronto Hospital suggests that at least $40 \%$ of antibiotic days are eligible for early 
conversion to oral therapy (personal communication). A similar survey of patients at Mount Sinai Hospital in Toronto revealed that $40 \%$ of patients receiving a thirdgeneration cephalosporin were eligible for oral therapy after $72 \mathrm{~h}$ of intravenous therapy (19). With an annual antibiotic expenditure of just under $\$ 3$ million at The Toronto Hospital, the implementation of an oral conversion program for only 12 antimicrobials results in an estimated crude cost savings of \$450,000 per year. Benefits to the patients also accrue, including the elimination of adverse events associated with intravenous therapy, increase of patient comfort and mobility if no intravenous therapy is required, and facilitation of a more active tangible role for the patient in his/her own treatment, not to mention the potential for early discharge. The implementation of a formalized early oral conversion program for hospitalized patients represents an ideal total quality management project and has a wide applicability for institutions across Canada. The potential for significant and meaningful cost savings in conjunction with improved quality of patient care on a national scale represents a unique opportunity that must not go unrecognized.

\section{REFERENCES}

1. Kunin CM. The responsibility of the infectious disease community for the optimal use of antimicrobial agents. $\mathrm{J}$ Infect Dis 1985;151:388-98.

2. Hess DA, Mahoney CD, Johnson PN, et al. Integration of clinical and administrative strategies to reduce expenditures for antimicrobial agents. Am J Hosp Pharm 1990;47:585-91.

3. Guglielmo BJ, Brooks GF. Antimicrobial therapy: Cost-benefit considerations. Drugs 1989;38:473-80.

4. Quintiliani R, Nightingale $\mathrm{CH}$. Antimicrobials and therapeutic decision making: A historical perspective. Pharmacotherapy 1991;11:65-135.

5. Ramirez J, Srinath L, Akee S, Raff M. Switch therapy with oral cefixime after intravenous third generation cephalosporin for the treatment of community-acquired pneumonia. 18th International Congress of Chemotherapy, Stockholm, Sweden 1993. (Abst 1375)

6. Frighetto L, Nickoloff D, Mortimusen SM, Marndani FS, Jewesson PJ. Intravenous-to-oral step-down program: Four years of experience in a large teaching hospital. Ann
Pharmacother 1992;26:1447-51.

7. Briceland LL, Nightingale $\mathrm{CH}$, Quintiliani R, Cooper BW, Smith KS. Antibiotic streamlining from combination therapy to monotherapy utilizing an interdisciplinary approach. Arch Intern Med 1988;148;2019-22.

8. Ehrenkranz NJ, Nerenberg DE, Shultz JM, Slater KC. Intervention to discontinue parenteral antimicrobial therapy in patients hospitalized with pulmonary infections: Effect on shortening patient stay. Infect Control Hosp Epidemiol 1992;13:21-32.

9. Wollschlager CM, Raoof S, Khan FA, et al. A controlled comparative study of ciprofloxacin versus ampicillin in treatment of bacterial respiratory tract infections. Am J Med 1987;82(Suppl 4A):164-8.

10. Kulhanjian K, Dunphy MG, Hamstra S, et al. Randomized comparative study of ampicillin/sulbactam vs ceftriaxone for treatment of soft tissue and skeletal infections in children. Pediatr Infect Dis J 1989;8:605-10.

11. Gentry LO, Rodriguez-Gomez G, Zeluff BJ, et al. A comparative evaluation of oral ofloxacin versus intravenous cefotaxime therapy for serious skin and skin structure infections. Am J Med 1989;87(Suppl 6C):31s-6s

12. Kolyvas E, Ahronheim G, Marks MI, et al. Oral antibiotic therapy of skeletal infections in children. Pediatrics 1980;65:867-71.

13. Black J, Hunt TL, Godley PJ, et al. Oral antimicrobial therapy for adults with osteomyelitis or septic arthritis. J Infect Dis 1987:155:968-72.

14. Lesse AJ, Freer C, Salata RA, et al. Oral ciprofloxacin therapy for Gram-negative bacillary osteomyelitis. Am J Med 1987;82(Suppl 4A):247-52.

15. Nelson JD, Bucholz RW, Kusmiesz H, et al. Benefits and risks of sequential parenteral-oral cephalosporin therapy for suppurative bone and joint infections. J Pediatr Orthop 1982;2:255-63.

16. Handsfield HH, Wiesner PJ, Holmes KK. Treatment of gonococcal dermatitis-arthritis syndrome. Ann Intern Med 1976;84:661-7.

17. Wainer JF, Perkins RL, Cordero L. Metronidazole therapy of anaerobic bacteraemia, meningitis, and brain abscess. Arch Intern Med. 1979;139:167-9.

18. Wang JC, Conly JM, Shafran SD. Appropriateness of metronidazole use in a teaching hospital. Am J Hosp Pharm 1989;46:1385-9.

19. McNaught A, Kozyrskyj A. Intravenous-to-oral stepdown program. Drug Info Bull Mt Sinai Hosp 1993:15.

John M Conly MD FRCPC Toronto, Ontario

Stephen D Shafran MD FRCPC Edmonton, Alberta

We are interested in producing a high quality product for our readers with regard to the topics and content of the Infectious Disease Notes. We are interested in hearing from you as a reader about any major likes, dislikes or comments about either the Adult or Pediatric ID Notes. We are also keen to know your ideas and suggestions for topics that should be covered in the ID Notes section. Please forward any information you have by fax or letter to:

\author{
ID Notes Survey \\ The Canadian Journal of Infectious Diseases \\ Pulsus Group Inc \\ 2902 South Sheridan Way \\ Oakville, Ontario L6J 7L6 \\ Telephone (905) 829-4770, Fax (905) 829-4799
}




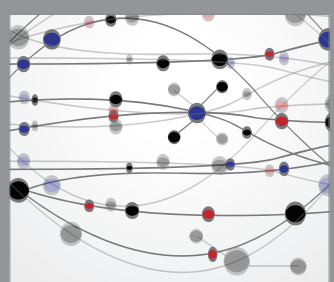

The Scientific World Journal
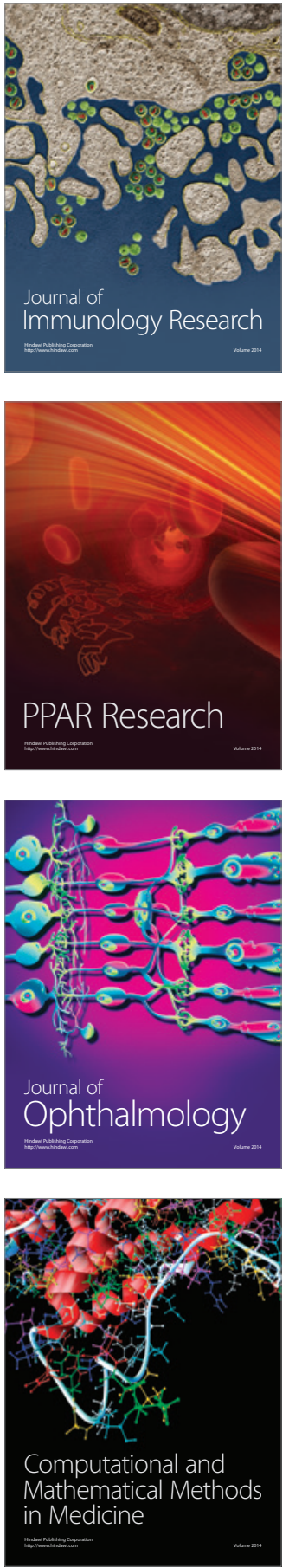

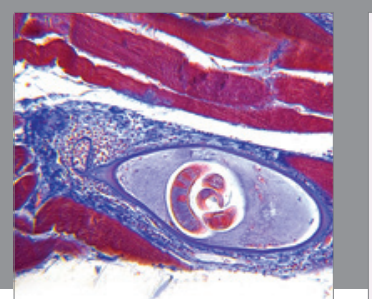

Gastroenterology Research and Practice

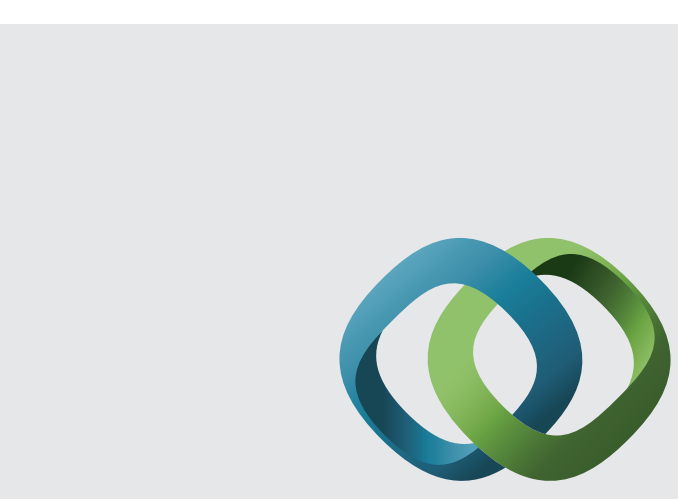

\section{Hindawi}

Submit your manuscripts at

http://www.hindawi.com
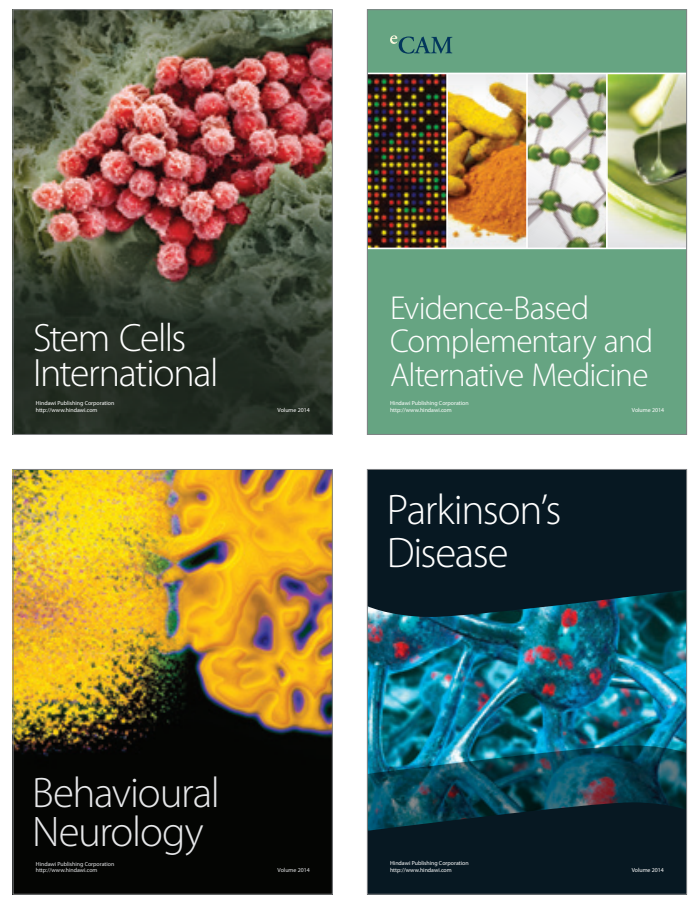
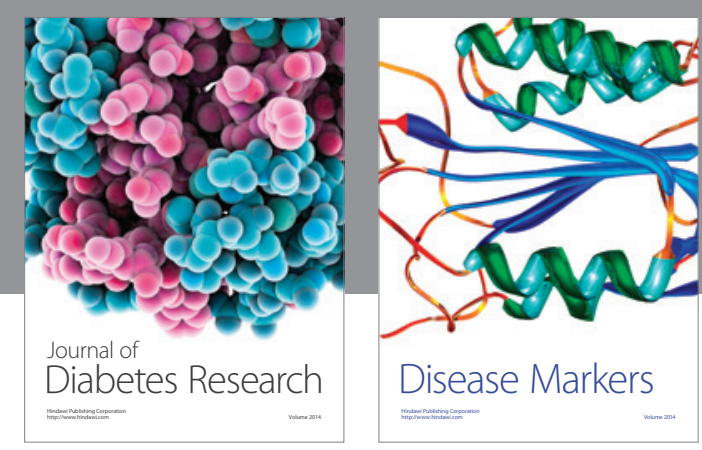

Disease Markers
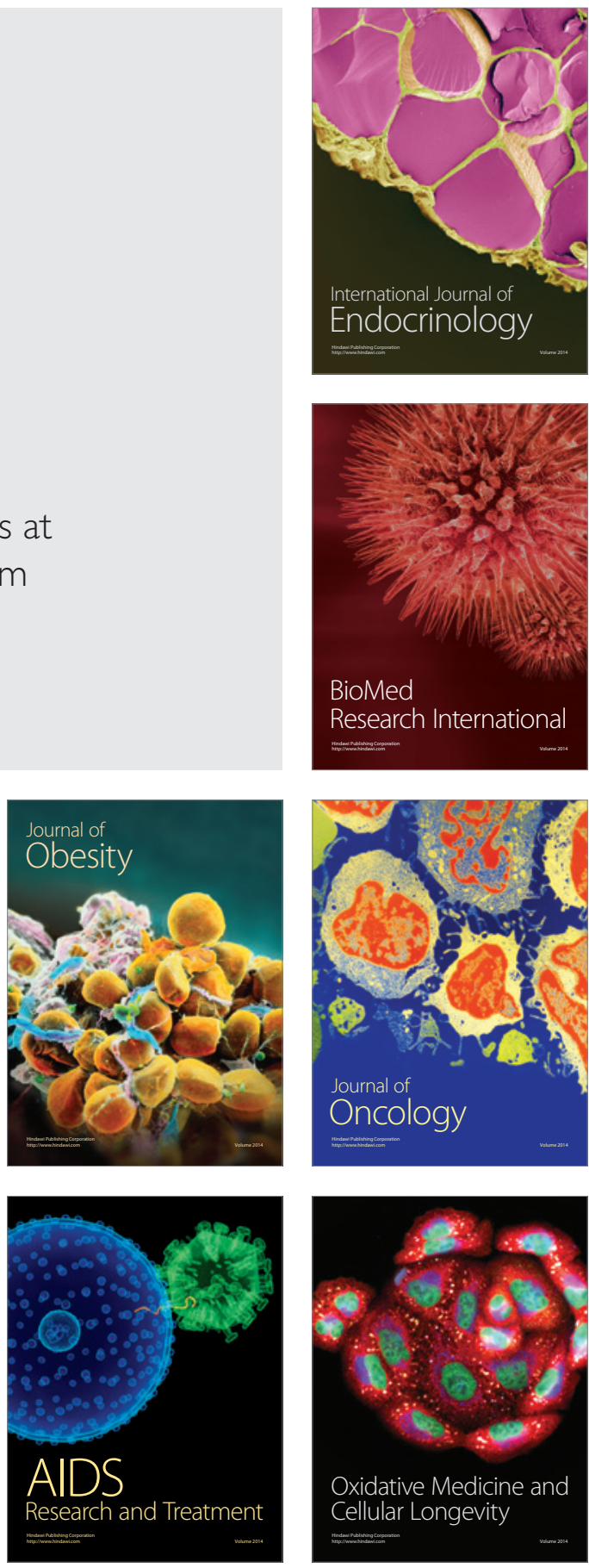